\title{
Liquid Water Path Steady States in Stratocumulus: Insights from Process-Level Emulation and Mixed-Layer Theory
}

\author{
FABIAN HOFFMANN
}

Cooperative Institute for Research in Environmental Sciences, University of Colorado Boulder, and Chemical Science Laboratory, NOAA/Earth System Research Laboratories, Boulder, Colorado

FRANZISKA GLASSMEIER ${ }^{\mathrm{a}}$

Wageningen University and Research, Wageningen, Netherlands, and Chemical Science Laboratory, NOAA/Earth System Research Laboratories, Boulder, Colorado

TAKANOBU YAMAGUCHI

Cooperative Institute for Research in Environmental Sciences, University of Colorado Boulder, and Chemical Science Laboratory, NOAA/Earth System Research Laboratories, Boulder, Colorado

\author{
GRAHAM FEINGOLD
}

Chemical Science Laboratory, NOAA/Earth System Research Laboratories, Boulder, Colorado

(Manuscript received 9 September 2019, in final form 4 March 2020)

\begin{abstract}
Stratocumulus clouds constitute one of the largest negative climate forcings in the global radiation budget. This forcing is determined, inter alia, by the cloud liquid water path (LWP), which we analyze using a combination of Gaussian process emulation and mixed-layer theory. For nocturnal, nonprecipitating stratocumuli, we show that LWP steady states constitute an equilibrium primarily between radiative cooling and entrainment warming and drying. These steady states are approached from lower LWPs due to reduced entrainment, while higher LWPs are depleted by stronger entrainment. An analytical solution for the LWP steady state reveals not only the environmental conditions in which a stratocumulus cloud can be maintained, but also distinct analytical properties of the entrainment velocity that are required for a stable LWP steady state that opposes perturbations. In particular, the results highlight the importance of an entrainment velocity that increases strictly monotonically with the LWP if stratocumuli are to attain a stable LWP steady state. This is demonstrated through analysis of two commonly used mixed-layer entrainment parameterizations.
\end{abstract}

\section{Introduction}

Due to their high albedo, large cloud cover, and low altitude, stratocumulus clouds constitute a major negative forcing in the global radiation budget (e.g., Boucher et al. 2013). However, various processes alter their radiative properties and even imperil their existence. While longwave radiative cooling is the main driver for

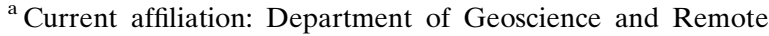
Sensing, Faculty of Civil Engineering and Geosciences, Delft University of Technology, Delft, Netherlands.
}

Corresponding author: Fabian Hoffmann, fabian.hoffmann@ noaa.gov convection and hence condensation, which is essential for the buildup to the cloud, radiative cooling also controls the entrainment of free-tropospheric air, which warms and dries and hence thins the cloud (e.g., Mellado 2017). Furthermore, precipitation may transform closed-cell stratocumuli into an open-cell state with a lower cloud fraction and hence a smaller cloud radiative effect (e.g., Sharon et al. 2006). Stratocumuli also tend to transition into shallow cumuli as a result of surface decoupling, which typically occurs when these clouds advect equatorward over warmer sea surface temperatures (e.g., Albrecht et al. 1995). Yet, the observed range of stratocumulus liquid water paths (LWPs) is astonishingly narrow from 40 to $150 \mathrm{~g} \mathrm{~m}^{-2}$ (e.g., Wood 2012).

Therefore, to understand stratocumuli, it is necessary to capture the potential range of environmental conditions 
affecting the balance of the aforementioned cloud processes. This, however, is only marginally possible in the typical modeling of stratocumulus clouds based on individual case studies, for example, the frequently applied Global Energy and Water Cycle Experiment (GEWEX) intercomparison cases based on measurement campaigns (Duynkerke et al. 1999; Stevens et al. 2005; Ackerman et al. 2009). Accordingly, only a narrow region of the possible state space is captured, limiting an integrated understanding of stratocumuli. Observations, either from satellites or permanent ground-based facilities, on the other hand, capture the natural variability of stratocumuli across the globe or at a specific region (e.g., McComiskey et al. 2009; Goren and Rosenfeld 2015), but they lack the depth of processlevel insight only available from detailed modeling.

To overcome this issue, we will use Gaussian process emulation (Rasmussen and Williams 2006; O'Hagan 2006) to extend the state space available from (a comparably small number of) high-resolution large-eddy simulations (LESs), following our first publication employing this technique (Glassmeier et al. 2019). That study showed that the multidimensional phase space necessary for the representation of stratocumuli can be successfully reduced to a two-dimensional state space, defined by LWP and cloud droplet number concentration $N$ only. In doing so, interesting metalevel characteristics of stratocumulus clouds and their radiative properties, which are primarily determined by the state-space dimensions LWP and $N$, can be revealed in a concise and comprehensive way (see also Fig. 1 below): First, stratocumuli with a mean radius at cloud top larger than $12 \mu \mathrm{m}$ cause a rapid decrease in $N$ as a result of the onset of precipitation (e.g., Gerber 1996). Second, all stratocumuli tend to approach a similar LWP of about $60 \mathrm{~g} \mathrm{~m}^{-2}$, which is especially prominent in the nonprecipitating part of the state space.

While this LWP steady-state behavior must result from a stratocumulus approaching the balance between longwave radiative cooling and entrainment warming and drying, the underlying processes are not well understood. One major reason for this lack of knowledge is the uncertainty in the representation of entrainment in LES (e.g., Stevens et al. 2005) but also in mixed-layer models (e.g., Lilly 1968), a process that has a major influence on the LWP (e.g., Zhu et al. 2005). We will therefore combine mixed-layer theory (section 2) and the aforementioned LES-based Gaussian process emulation (section 3) to understand LWP steady states not only for a single case study, but for an extended state space. In spite of the inherent limitations of these approaches, we argue that together they bring significant added value by generalizing our qualitative understanding. Finally, this analysis will lead to an analytical form of the LWP steady state depending explicitly on environmental parameters such

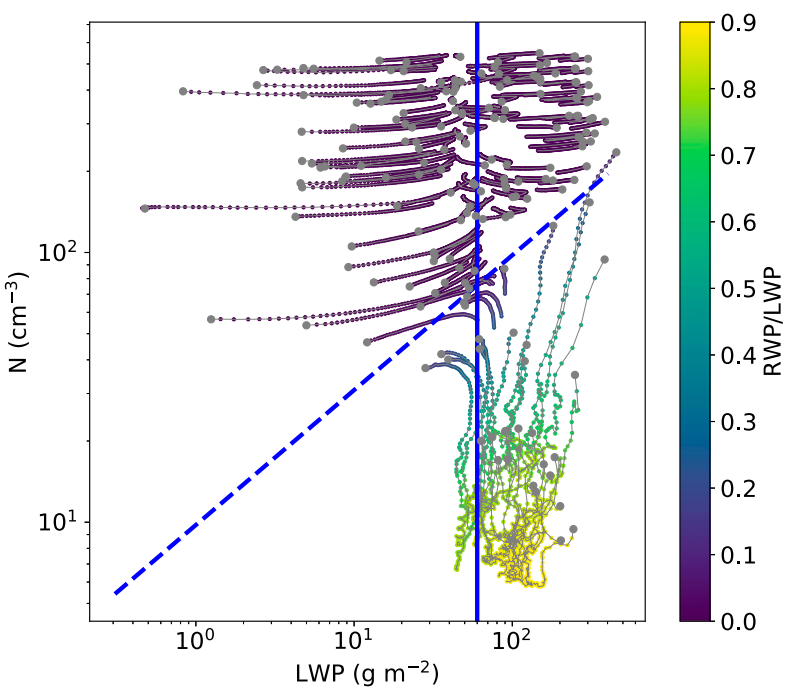

FIG. 1. A sample of the 187 LESs used to train the emulators used in Glassmeier et al. (2019) and in this study. The gray dot indicates the start of each trajectory, and the colored dots the ratio of the rainwater path (vertically integrated liquid water resulting from droplets larger than $25 \mu \mathrm{m})$ to the LWP. The dashed blue line limits the precipitating state space (below line) in which the mean radius at cloud top exceeds $12 \mu \mathrm{m}$. The continuous blue line indicates the LWP steady state at $60 \mathrm{~g} \mathrm{~m}^{-2}$. [Figure based on Fig. 1 by Glassmeier et al. (2019) licensed under CC BY 4.0 (https://creativecommons.org/licenses/by/4.0), with changes.]

as surface fluxes, radiation, and subsidence, revealing universal properties of the entrainment velocity required to attain a stable LWP steady state (section 4).

\section{Mixed-layer theory}

Based on the initial work by Lilly (1968), the development of a stratocumulus-topped boundary layer can be successfully modeled by predicting the development of a single mixed layer, using (at least) three parameters (e.g., Baker and Charlson 1990; Wood 2007; Caldwell and Bretherton 2009; Dal Gesso et al. 2014; van der Dussen et al. 2014). These are the liquid water potential temperature,

$$
z_{i} \frac{d \theta_{l}}{d t}=S_{\theta_{l}}+w_{e} \Delta \theta_{l}+R_{\theta_{l}}+P_{\theta_{l}},
$$

total water mixing ratio,

$$
z_{i} \frac{d q_{t}}{d t}=S_{q_{t}}+w_{e} \Delta q_{t}+P_{q_{t}}
$$

and height of the stratocumulus-topped boundary layer,

$$
\frac{d z_{i}}{d t}=w_{e}+w_{s} .
$$

Here, $S_{\theta_{l}}$ and $S_{q_{t}}$ are the kinematic surface fluxes of $\theta_{l}$ and $q_{t}$, respectively; $\Delta \theta_{l}$ and $\Delta q_{t}$ are the corresponding 
differences, or jumps, of $\theta_{l}$ and $q_{t}$ between the free troposphere and the boundary layer; $w_{e}$ is the entrainment velocity; $R_{\theta_{l}}$ is the heating or cooling rate by the emission or absorption of radiation; $P_{\theta_{l}}$ and $P_{q_{t}}$ represent the respective impact of precipitation; and $w_{s}$ is the subsidence velocity.

The main purpose of this study is to understand changes in the LWP, defined as

$$
\mathrm{LWP}=\int_{z_{b}}^{z_{i}} \rho_{a}(z) q_{l}(z) d z=\frac{1}{2} \Gamma_{q_{l}} \overline{\rho_{a}}\left(z_{i}-z_{b}\right)^{2}
$$

assuming an adiabatic cloud. Here, $q_{l}$ is the liquid water mixing ratio; $\Gamma_{q_{l}}$ describes the increase of $q_{l}$ with height (depending on temperature and pressure); $\rho_{a}$ is the density of air, with the overbar representing a cloudlayer average; and $z_{b}$ is the cloud-base height. As previously shown by Wood (2007), van der Dussen et al. (2014), and Ghonima et al. (2015), the temporal change of LWP in the mixed-layer framework can be derived from Eq. (4) using the aforementioned prognostic equations [Eqs. (1)-(3)]:

$$
\begin{aligned}
\frac{d \mathrm{LWP}}{d t} & =\Gamma_{q_{l}} \overline{\rho_{a}}\left(z_{i}-z_{b}\right)\left(\frac{d z_{i}}{d t}-\frac{d z_{b}}{d t}\right) \\
& =\Gamma_{q_{l}} \overline{\rho_{a}}\left(z_{i}-z_{b}\right)\left[\frac{d z_{i}}{d t}-\left(\frac{\partial z_{b}}{\partial q_{t}} \frac{d q_{t}}{d t}+\frac{\partial z_{b}}{\partial \theta_{l}} \frac{d \theta_{l}}{d t}\right)\right] \\
& =S_{\mathrm{LWP}}+E_{\mathrm{LWP}}+R_{\mathrm{LWP}}+P_{\mathrm{LWP}}+M_{\mathrm{LWP}},
\end{aligned}
$$

with $\partial z_{b} / \partial q_{t}=\left[R_{d} T_{b} /\left(g q_{t}\right)\right]\left[1-l_{v} R_{d} /\left(c_{p} R_{v} T_{b}\right)\right]^{-1}<0$ and $\partial z_{b} / \partial \theta_{l}=\left[c_{p} T_{b} /\left(g \theta_{l}\right)\right]\left[1-c_{p} R_{v} T_{b} /\left(l_{v} R_{d}\right)\right]^{-1}>0$, where $R_{d}$ and $R_{v}$ are the specific gas constants for dry air and water vapor, respectively; $T_{b}$ is the temperature at cloud base; $g$ is the acceleration due to gravity; $l_{v}$ is the latent heat of vaporization; and $c_{p}$ is the specific heat capacity at constant pressure. (See Ghonima et al. (2015) for a detailed derivation of $\partial z_{b} / \partial q_{t}$ and $\partial z_{b} / \partial \theta_{l}$.)

By introducing Eqs. (1)-(3) into Eq. (5), the terms $S_{\mathrm{LWP}}, E_{\mathrm{LWP}}, R_{\mathrm{LWP}}, P_{\mathrm{LWP}}$ and $M_{\mathrm{LWP}}$ can be assigned to specific physical processes affecting the LWP, that is, surface fluxes

$$
S_{\mathrm{LWP}}=-\Gamma_{q_{l}} \overline{\rho_{a}} \frac{z_{i}-z_{b}}{z_{i}}\left(\frac{\partial z_{b}}{\partial q_{t}} S_{q_{t}}+\frac{\partial z_{b}}{\partial \theta_{l}} S_{\theta_{l}}\right),
$$

entrainment of free-tropospheric air

$$
E_{\mathrm{LWP}}=-\Gamma_{q_{l}} \bar{\rho}_{a} \frac{z_{i}-z_{b}}{z_{i}}\left(\frac{\partial z_{b}}{\partial q_{t}} w_{e} \Delta q_{t}+\frac{\partial z_{b}}{\partial \theta_{l}} w_{e} \Delta \theta_{l}\right)
$$

radiation

$$
R_{\mathrm{LWP}}=-\Gamma_{q_{l}} \overline{\rho_{a}} \frac{z_{i}-z_{b}}{z_{i}} \frac{\partial z_{b}}{\partial \theta_{l}} R_{\theta_{l}}
$$

surface precipitation

$$
P_{\mathrm{LWP}}=-\Gamma_{q_{l}} \overline{\rho_{a}} \frac{z_{i}-z_{b}}{z_{i}}\left(\frac{\partial z_{b}}{\partial q_{t}} P_{q_{t}}+\frac{\partial z_{b}}{\partial \theta_{l}} P_{\theta_{l}}\right)
$$

and motion of the cloud top

$$
M_{\mathrm{LWP}}=\Gamma_{q_{l}} \overline{\rho_{a}}\left(z_{i}-z_{b}\right)\left(w_{e}+w_{s}\right)
$$

The derivation also shows that the terms (6)-(9) affect $z_{b}$, while only the last term (10) constitutes a forcing on $z_{i}$. In the following section, we will diagnose these terms from LESs and emulate them in the LWP- $N$ state space to understand how stratocumuli approach a steady-state LWP.

\section{Process-level emulation}

To build the emulator, the LWP tendency terms (6)(10) are diagnosed from 187 selected LESs as explained in Glassmeier et al. (2019). Their temporal development is illustrated in Fig. 1. All simulations are carried out with the System for Atmospheric Modeling (SAM) (Khairoutdinov and Randall 2003) with two-moment cloud microphysics (Feingold et al. 1998). The simulation setups follow, with changes, the marine stratocumulus case by Ackerman et al. (2009), itself based on the second research flight of the DYCOMS II campaign (Stevens et al. 2003). All simulations use a model domain of $48 \mathrm{~km} \times 48 \mathrm{~km}$ to allow for the reasonable representation of the organization of open-cell stratocumuli (e.g., Savic-Jovcic and Stevens 2008; Wang and Feingold 2009; Kazil et al. 2017), and a horizontal and vertical grid spacing of 200 and $10 \mathrm{~m}$, respectively. The simulation duration is $12 \mathrm{~h}$ (nocturnal). Radiative cooling and heating rates are determined interactively using the Rapid Radiative Transfer Model (RRTMG) by Clough et al. (2005). Dynamical surface fluxes for sensible $\left(16 \mathrm{~W} \mathrm{~m}^{-2}\right)$ and latent heat $\left(93 \mathrm{Wm}^{-2}\right)$ are prescribed as constant and not varied. Similarly, the subsidence is determined as $w_{s}=-z_{i} D$, prescribing a large-scale divergence of $D=3.75 \times 10^{-6} \mathrm{~s}^{-1}$ for all simulations. We vary, however, the initial conditions for the liquid water potential temperature (284 $\leq$ $\left.\theta_{l} \leq 294 \mathrm{~K}\right)$, the total water mixing ratio $(6.5 \leq$ $\left.q_{t} \leq 10.5 \mathrm{~g} \mathrm{~kg}^{-1}\right)$, the aerosol number concentration $\left(30 \leq N_{a} \leq 500 \mathrm{~cm}^{-3}\right)$, the initial boundary layer height $\left(500 \leq z_{i} \leq 1300 \mathrm{~m}\right)$, and the jumps of temperature and humidity $\left(6 \leq \Delta \theta_{l} \leq 10 \mathrm{~K}\right.$ and $-10 \leq \Delta q_{t} \leq-6 \mathrm{~g} \mathrm{~kg}^{-1}$, respectively) systematically within the ensemble of simulations. The reader is referred to Glassmeier et al. (2019) for more details on the setup of the simulations and for technical details on the Gaussian process emulation used below. In brief, Gaussian process emulation is an interpolation approach for sparse, presumably 
smoothly varying data. Here, we use this approach to emulate the mixed-layer LWP tendencies resulting from surface fluxes, entrainment, radiation, precipitation, motion of the cloud top, and the sum of these terms, corresponding to Eqs. (6)-(10) and (5), presented in Fig. 2 as a function of LWP and $N$ only, that is, a reduced state space to which the multidimensional space of the training data can be successfully reduced, as further detailed in Glassmeier et al. (2019).

Note that the following analysis assumes that mixedlayer theory is applicable, which might be violated if the stratocumulus decouples from the surface. As suggested by Nicholls (1984), this might be the case for strongly entraining or strongly precipitating stratocumuli. Nevertheless, as shown by others, the mixed-layer analog yields useful insights.

Positive LWP tendencies are mainly caused by surface fluxes (Fig. 2a) and radiation (Fig. 2c). Note that the effect of surface fluxes is positive since the prescribed moistening exceeds the warming, as is typical for stratocumuli. Since the surface fluxes are prescribed as constant, their effect on the LWP is also almost constant over the entire state space. For larger LWPs, their impact on LWP increases nonetheless. This is due to the quadratic dependence of the LWP on the cloud depth, resulting in a prefactor of $z_{i}-z_{b}$ affecting all LWP tendencies [see Eqs. (6)-(10)]. The LWP tendency due to radiative cooling increases significantly toward larger LWP values, reflecting the increased emission of longwave radiation for an optically thicker cloud. However, this effect saturates for LWPs larger than $40 \mathrm{~g} \mathrm{~m}^{-2}$ (e.g., Garrett et al. 2002). The additional increase for larger LWPs results from the aforementioned cloud-depth prefactor directly increasing the effect of radiation on LWP.

The warming and drying by entrainment (Fig. 2b) constitutes the strongest negative tendency on LWP, but also exhibits the most complex dependence on LWP and $N$. Entrainment in stratocumuli is primarily driven by negatively buoyant downdrafts from the cloud top caused by cooling due to the emission of longwave radiation and the evaporation of liquid water mixed with free-tropospheric air, both increasing for a larger LWP. The dependence of entrainment on $N$ results from two processes: First, the potential for evaporative cooling decreases when sedimentation removes liquid water from the cloud top, reducing entrainment for clouds containing larger droplets (Ackerman et al. 2004; Bretherton et al. 2007). Therefore, this effect, frequently termed the sedimentation-entrainment feedback, is posed as proportional to the sedimentation velocity

$$
w_{\text {sed }} \propto r \propto \frac{L W P^{1 / 6}}{N^{1 / 3}},
$$

assuming that $w_{\text {sed }}$ is proportional to the droplet radius $r$, which is obtained from the liquid water content at cloud top given by $q_{l}\left(z_{i}\right)=\Gamma_{q_{l}}\left(z_{i}-z_{b}\right) \propto \mathrm{LWP}^{1 / 2}$. Mellado (2017) argues that the sedimentation-entrainment feedback (SEF) becomes significant when $w_{\text {sed }}$ exceeds the entrainment velocity $w_{e}$. For typical conditions, the entrainment velocity can be assumed to be $\mathscr{O}(1) \mathrm{cm} \mathrm{s}^{-1}$, corresponding to the sedimentation velocity of a droplet with a radius of $\mathscr{Q}(10) \mu \mathrm{m}$. The isoline corresponding to this value is displayed as SEF in Fig. 2, and entrainment is expected to be increasingly suppressed in the state space below.

Second, entrainment increases with $N$ since the larger integral droplet surface, as a result of smaller but more numerous droplets, accelerates evaporation of liquid water at the cloud top, which triggers stronger downdrafts (Wang et al. 2003). This effect, frequently termed the evaporation-entrainment feedback, can be assumed to be inversely proportional to the phase relaxation time scale,

$$
\tau_{\text {phase }}^{-1} \propto N r \propto N^{2 / 3} \mathrm{LWP}^{1 / 6},
$$

quantifying the time necessary for depleting a subsaturation by droplet evaporation and hence the time during which evaporative cooling triggers downdrafts. However, the resolution of typical LES is insufficient to resolve the spatial distribution of these subsaturations resulting from entrainment and mixing, which are as small as a couple of decimeters in stratocumuli (e.g., Lehmann et al. 2009). In fact, Hoffmann and Feingold (2019) showed that the evaporation-entrainment feedback is stronger in simulations in which these small-scale features are resolved. However, we can estimate the coarsegrained effect in our simulations by comparing $\tau_{\text {phase }}$ to the vertical advection time scale $\tau_{\mathrm{adv}}=\Delta z / w_{e} \approx 2000 \mathrm{~s}$, estimating the time for the cloud top to grow beyond one grid box of height $\Delta z=10 \mathrm{~m}$. During this time, the cloud top evaporates spuriously until the grid box is saturated (Stevens et al. 1996; Hoffmann 2016), potentially increasing entrainment. Since $\tau_{\text {adv }} \gg \tau_{\text {phase, }}$, with $\tau_{\text {phase }}<10$ s for typical stratocumuli, the entire state space is affected by this spurious evaporation-entrainment feedback. ${ }^{1}$ How entrainment is expected to increase toward larger $N$

\footnotetext{
${ }^{1}$ The physical evaporation-entrainment feedback, unresolved in our LES modeling, might occur if $\tau_{\text {mix }} \gg \tau_{\text {phase. The mixing time }}$ scale yields $\tau_{\text {mix }}=\left(l^{2} / \varepsilon\right)^{1 / 3} \approx 2 \mathrm{~s}$, using a typical kinetic energy dissipation rate of $\varepsilon=10 \mathrm{~cm}^{2} \mathrm{~s}^{-3}$ and assuming that the homogenization of free-tropospheric and cloudy air happens at a length scale of $l=10 \mathrm{~cm}$ in stratocumuli. Accordingly, one obtains the range primarily affected by the evaporation-entrainment feedback as approximately $N>100 \mathrm{~cm}^{-3}$ and LWP $>100 \mathrm{~g} \mathrm{~m}^{-2}$.
} 
(a) surface fluxes

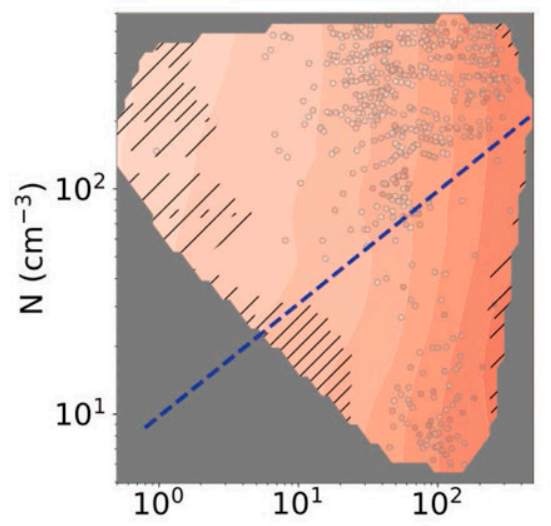

(c) radiation

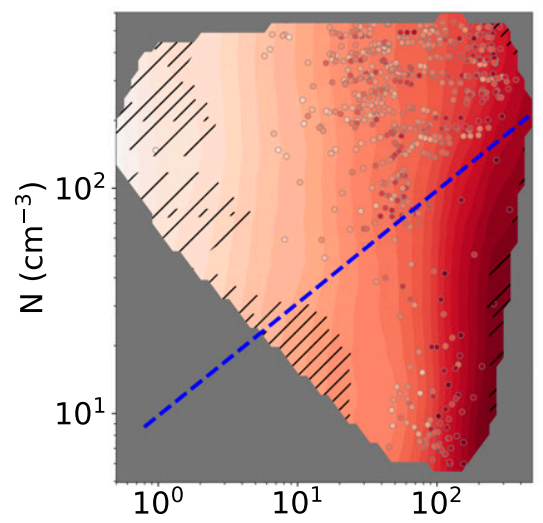

(e) motion of cloud top

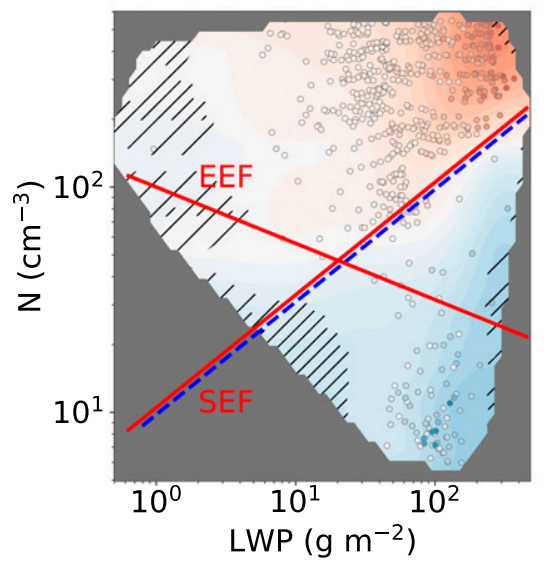

(b) entrainment

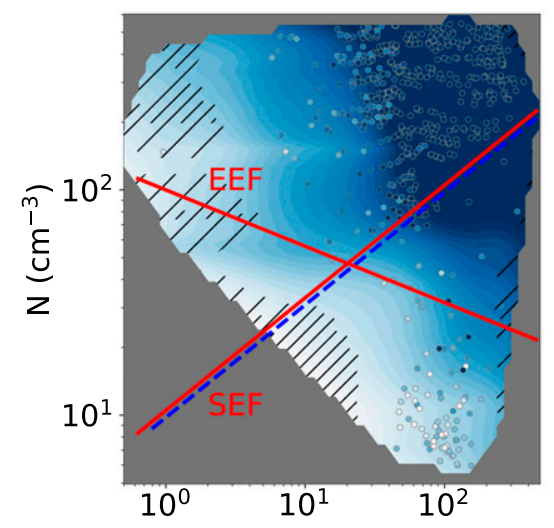

(d) precipitation

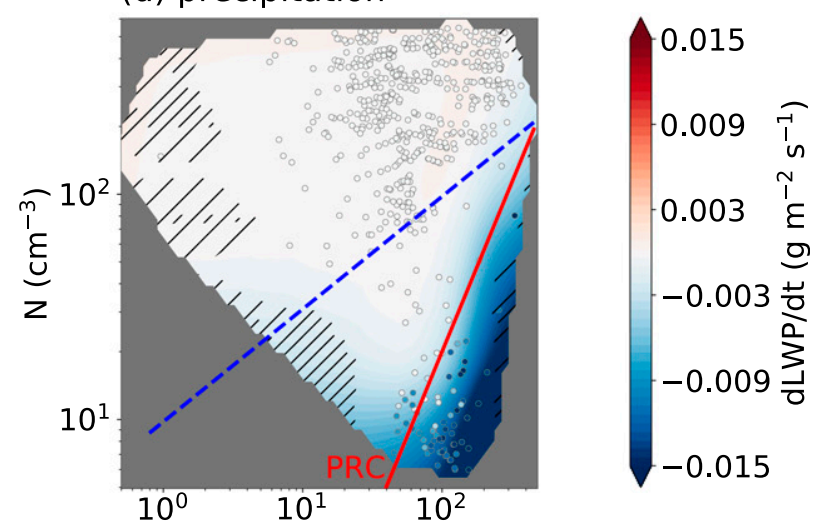

(f) total change

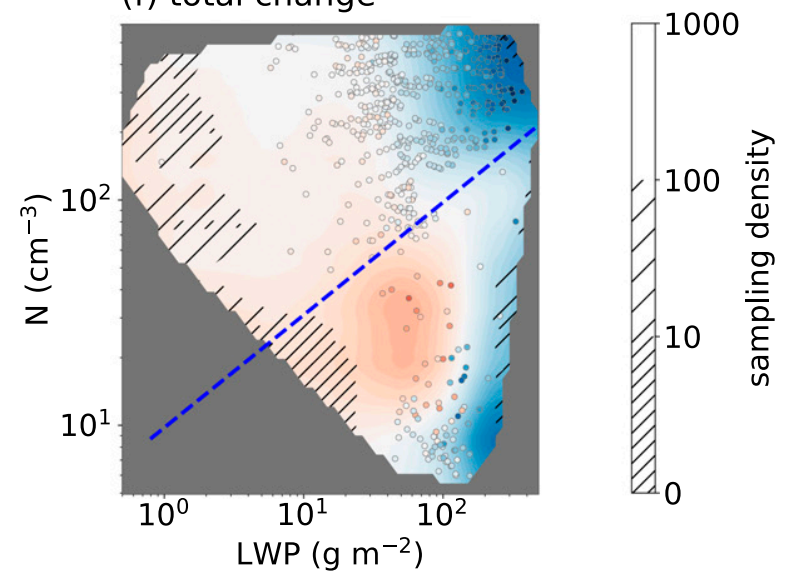

FIG. 2. Emulated LWP tendencies resulting from (a) surface fluxes, (b) entrainment, (c) radiation, (d) precipitation, (e) motion of the cloud top, and (f) the sum of these terms as a function of the LWP and $N$, corresponding to Eqs. (6)-(10) and (5). The dashed blue line indicates a cloud-top radius of $12 \mu \mathrm{m}$. Below this line precipitation becomes significant. The red lines indicate one isoline for the evaporation-entrainment feedback (EEF), sedimentation-entrainment feedback (SEF), and surface precipitation (PRC) as a function of LWP and $N$; the underlying equations are defined in the text. Validation data (diagnosed from LES modeling) are shown by color-filled circles with a gray outline. The hatching indicates the number of training points used to create the emulator per logarithmically spaced LWP- $N$ bin, indicating uncertain regions in the emulator (Glassmeier et al. 2019). 
due to the evaporation-entrainment feedback (EEF) is represented by the isoline EEF in Fig. 2, using the slope of $\tau_{\text {phase }}^{-1}$ as defined in Eq. (12).

Together with the aforementioned general increase of entrainment with LWP, the isolines SEF and EEF in Fig. 2 indicate that the strongest effect of entrainment is expected for the largest LWPs and the highest $N$, as seen in the upper-right part of Fig. 2b. Note, however, that the dependency of Eq. (7) on the jumps $\Delta q_{t}$ and $\Delta \theta_{l}$ complicates general conclusions since they constitute an uncontrolled-for variability on the effect of entrainment in the analyzed state space (Glassmeier et al. 2019).

Surface precipitation (Fig. 2d) contributes negatively to the LWP by heating and drying in the strongly precipitating parts of the state space (lower-right part), where raindrops are sufficiently large to reach the surface. Accordingly, this effect increases with the surface rain rate $R$. Kostinski (2008) argued that $R$ is proportional to the ratio of the cubed cloud thickness to $N$ :

$$
R \propto \frac{\left(z_{i}-z_{b}\right)^{3}}{N} \propto \frac{\mathrm{LWP}^{3 / 2}}{N} .
$$

Rain rates increase in lines parallel to the depicted isoline PRC toward larger LWP, capturing the emulated surface well.

The motion of the cloud top determines $z_{i}$ and therefore sets the upper bound of the cloud and hence the LWP (Fig. 2e). Since the motion of the cloud top depends on the difference between the entrainment and subsidence velocity, it is mainly controlled by the dependence of entrainment on LWP and $N$ (see Fig. 2b), while the subsidence contributes in a relatively uniform manner. Entrainment (positive tendencies) dominates in regions without precipitation (above the blue dashed line), while subsidence (negative tendencies) dominates in the precipitating part of the state space, where the sedimentation-entrainment feedback reduces entrainment. The potential increase in LWP due to entrainment, that is, a faster increase in cloud-top height than in cloud-base height (Randall 1984), does not occur since the generally negative effect of entrainment warming and drying (Fig. 2b) offsets the potential positive effects of the motion of the cloud top throughout the analyzed state space. Over the entire state space, however, the motion of the cloud top is almost negligible compared to the other processes discussed above, that is, the cloud base controls the LWP, not the cloud top.

The total change of LWP (Fig. 2f) shows two local minima and one local maximum in $d \mathrm{LWP} / d t$. The strongest negative LWP tendencies are caused by entrainment (highest LWP, highest $N$ ) and surface precipitation (highest LWP, lowest $N$ ). The strongest positive LWP tendency is also located in the precipitating region of the state space (below the dashed blue line), but the precipitation is not reaching the surface, inhibiting negative effects of precipitation on the LWP. Additionally, the sedimentation-entrainment feedback benefits from significant sedimentation in this region, counteracting the negative impacts of entrainment on the LWP. Furthermore, Fig. 2f also indicates a band of LWP steady states $(d \mathrm{LWP} / d t \approx 0)$ around $60 \mathrm{~g} \mathrm{~m}^{-2}$ with smaller values in the nonprecipitating and larger values in the precipitating part of the state space. These steady states are enclosed by negative (positive) LWP tendencies at larger (smaller) LWPs, driving the thinning (thickening) of stratocumuli toward the steady state, in agreement with Fig. 1. Overall, this indicates that the LWP steady state is a stable steady state, driving deviating LWPs toward the steady state.

To summarize this analysis, Figs. $3 \mathrm{a}-\mathrm{c}$ show cross sections through the state space at $N=50,100$, and $200 \mathrm{~cm}^{-3}$, respectively. The almost constant surface fluxes (orange line) can be identified as the main driver for the initiation of the cloud (LWP $<10 \mathrm{~g} \mathrm{~m}^{-2}$ ). However, the effects of entrainment (green) and radiation (blue) increase significantly with LWP, dominating all other tendencies for LWP $>10 \mathrm{~g} \mathrm{~m}^{-2}$. Note that the effect of entrainment also exhibits the strongest susceptibility to $N$, almost doubling its influence for an increase in $N$ from 50 to $200 \mathrm{~cm}^{-3}$ as discussed above. Surface precipitation (red) does not affect small LWPs, but its negative effect on the LWP increases quickly for LWP $>100 \mathrm{~g} \mathrm{~m}^{-2}$, only slightly modulated by $N$. Interestingly, the motion of the cloud top (purple) is negligible for the same LWP range not affected by surface precipitation (red). At higher LWPs, however, the effect of the motion of the cloud top on the LWP becomes negative $\left(N=50\right.$ and $\left.100 \mathrm{~cm}^{-3}\right)$ or positive $\left(N=200 \mathrm{~cm}^{-3}\right)$ as a result of the aforementioned strong $N$ dependency of entrainment. Combining all these tendencies (black), an LWP steady-state region $(d \mathrm{LWP} / d t \approx 0)$ can be identified for $N=100$ and $200 \mathrm{~cm}^{-3}$ for LWPs from 10 to $100 \mathrm{~g} \mathrm{~m}^{-2}$ and from 5 to $20 \mathrm{~g} \mathrm{~m}^{-2}$, respectively. An LWP steady state is also found for the $N=50 \mathrm{~cm}^{-3}$ cross section; however, it is reduced to a steep crossing of $d \mathrm{LWP} / d t=0$ at $\mathrm{LWP} \approx 150 \mathrm{~g} \mathrm{~m}^{-2}$. This steep slope can be attributed to the quick transition from the local maximum to the local minimum of $d \mathrm{LWP} / d t$ in the precipitating region discussed for Fig. $2 \mathrm{f}$ above. Note that this feature is absent for higher $N$. All in all, these data reemphasize that LWP steady states are framed by positive and negative LWP tendencies for smaller 
(a) $\mathrm{N}=50 \mathrm{~cm}^{-3}$

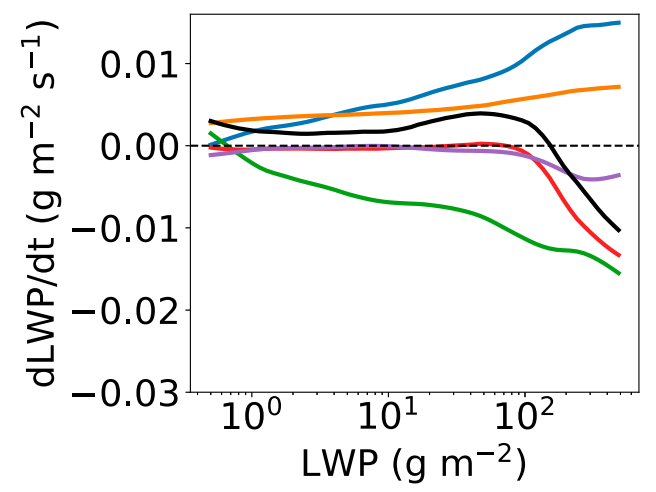

(b) $\mathrm{N}=100 \mathrm{~cm}^{-3}$

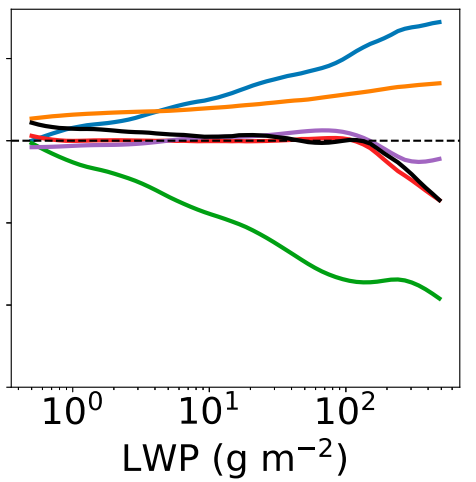

(c) $\mathrm{N}=200 \mathrm{~cm}^{-3}$

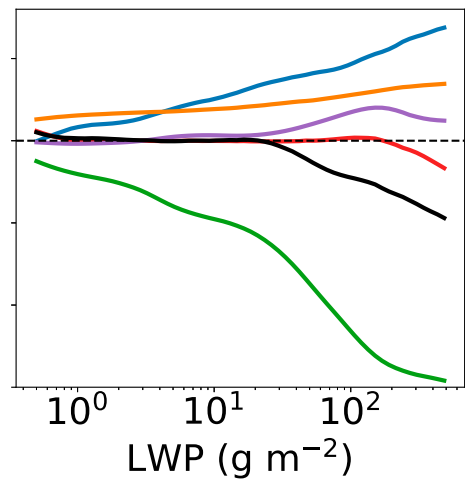

\section{- surface fluxes \\ - entrainment}

\section{- radiation \\ - precipitation}

- motion of cloud top

- total change

FIG. 3. Cross sections of the LWP- $N$ state space at (a) $N=50 \mathrm{~cm}^{-3}$, (b) $N=100 \mathrm{~cm}^{-3}$, and (c) $N=200 \mathrm{~cm}^{-3}$, showing the dependence of LWP tendencies on surface fluxes (orange line), entrainment (green), radiation (blue), precipitation (red), motion of cloud top (purple), and the total change (black).

and larger LWPs, respectively, making them stable, which will be analyzed analytically next.

\section{An analytic expression for the LWP steady state}

An analytic expression for the LWP steady state highlighted in the previous sections will now be derived from mixed-layer theory to understand its general dependence on radiation, temperature and humidity jumps, subsidence, and surface fluxes, thereby extending our comprehension of the previously presented emulators that are built from LES with fixed surface fluxes and a constant large-scale divergence for the subsidence, that is, environmental parameters that typically vary in nature.

First, we understand from the mixed-layer theory presented in section 2 that an LWP steady state requires that the cloud depth, $z_{i}-z_{b}$, be constant in time (neglecting changes in $\Gamma_{q_{l}}$ ):

$$
\frac{d z_{i}}{d t}-\frac{d z_{b}}{d t}=0
$$

Following the concept of slow manifolds introduced by Bretherton et al. (2010), the temporal changes in $z_{i}$ are slower than the thermodynamic adjustments of stratocumulus, mainly affecting $z_{b}$. Therefore, we can assume that $z_{i}$ is constant on shorter time scales, that is, the entrainment velocity is approximately balanced by the subsidence:

$$
\frac{d z_{i}}{d t}=0 \Leftrightarrow w_{e}=-w_{s} .
$$

Thus, $z_{b}$ needs to be constant to yield a constant LWP (neglecting effects of precipitation):

$$
\begin{aligned}
\frac{d z_{b}}{d t} & =\frac{\partial z_{b}}{\partial q_{t}} \frac{d q_{t}}{d t}+\frac{\partial z_{b}}{\partial \theta_{l}} \frac{d \theta_{l}}{d t} \\
& =\frac{\partial z_{b}}{\partial q_{t}} \frac{1}{z_{i}}\left(S_{q_{t}}+w_{e} \Delta q_{t}\right)+\frac{\partial z_{b}}{\partial \theta_{l}} \frac{1}{z_{i}}\left(S_{\theta_{l}}+w_{e} \Delta \theta_{l}+R_{\theta_{l}}\right) \\
& =0
\end{aligned}
$$

Next, an expression for $R_{\theta_{l}}$ is derived from the boundary layer integral of the divergence of the net radiative flux $F(z)$, which is parameterized as in Ackerman et al. (2009), closely approximating the more complex radiative transfer calculations used in our LES modeling:

$$
\begin{aligned}
R_{\theta_{l}} & =\frac{-1}{\overline{\rho_{a}} c_{p}} \int_{0}^{z_{i}} \frac{d F(z)}{d z} d z \\
& =\frac{-1}{\overline{\rho_{a}} c_{p}}\left(F_{0}-F_{1}\right)[1-\exp (-\kappa \mathrm{LWP})]
\end{aligned}
$$

where $F_{0}$ and $F_{1}$ denote the maximum possible net radiative flux at the cloud top and surface, respectively, regulated by the product of LWP and $\kappa$, the latter controlling the absorptance of the cloud. For a large LWP, the divergence of the net radiative flux across the boundary layer approaches $F_{0}-F_{1}$, and therefore will henceforth be called the potential radiation jump, and describes the maximum possible radiative cooling or heating. Note that in the LES modeling, $F_{0}$ 
and $F_{1}$ are determined by the temperature of the cloud and the sea surface, respectively.

Solving Eq. (16) for $w_{e}$ results in an entrainment velocity that is required to maintain a steady-state cloud base, and hence an LWP steady state:

$$
w_{e} \stackrel{!}{=} w_{e, \mathrm{LWP}} \equiv-\frac{\zeta S_{q_{t}}+S_{\theta_{l}}+R_{\theta_{l}}}{\zeta \Delta q_{t}+\Delta \theta_{l}},
$$

where $\zeta=\left(\partial z_{b} / \partial q_{t}\right) /\left(\partial z_{b} / \partial \theta_{l}\right) \approx-2400$ to $-1400 \mathrm{~K}$ for the range of values used to initialized the LESs in section 3. Note that Eq. (18) is a first condition to be met by $w_{e}$ to create an LWP steady state (as indicated by the exclamation point above the equals sign), but it does not imply a stable steady state. Furthermore, $w_{e, \mathrm{LWP}}$ should not be seen as a fluid-dynamical description of the entrainment velocity. In fact, $w_{e, \mathrm{LWP}}$ is determined only to ensure a steady-state cloud base, and hence steady-state LWP. Figure 4 compares $w_{e, \mathrm{LWP}}$ (black line) to entrainment velocity parameterizations that have been derived from fluid-dynamical considerations: $w_{e, S}=-\eta R_{\theta_{l}} / \Delta \theta_{l}$ (orange line) by Stevens (2006) and $w_{e, \mathrm{NT}}$ (blue line) by Nicholls and Turton (1986), to whom the reader is referred for the (more complex) equations leading to $w_{e, \mathrm{NT}}$. Note that the aforementioned entrainment velocity parameterization has been used in many mixed-layer studies so far; it has also been found to compare reasonably well with LES modeling if tuned correctly (e.g., Uchida et al. 2010). To match our simulations, we also tuned the entrainment efficiencies of $w_{e, S}$ and $w_{e, \mathrm{NT}}$ to $\eta=$ 0.74 and 0.28 , respectively. Both values are slightly higher than those recommended in the literature [0.7 as suggested by Dal Gesso et al. (2014) and 0.2 by Turner (1973), respectively], but they ensure that $w_{e, S}=w_{e, \mathrm{NT}}=w_{e, \mathrm{LWP}}$ for $\mathrm{LWP}=60 \mathrm{~g} \mathrm{~m}^{-2}$, that is, the steady state observed in our simulations. In fact, $w_{e, \mathrm{LWP}}=w_{e, S}$ for all LWP $>60 \mathrm{~g} \mathrm{~m}^{-2}$, indicating that all these LWPs are in a steady state, allowing them to

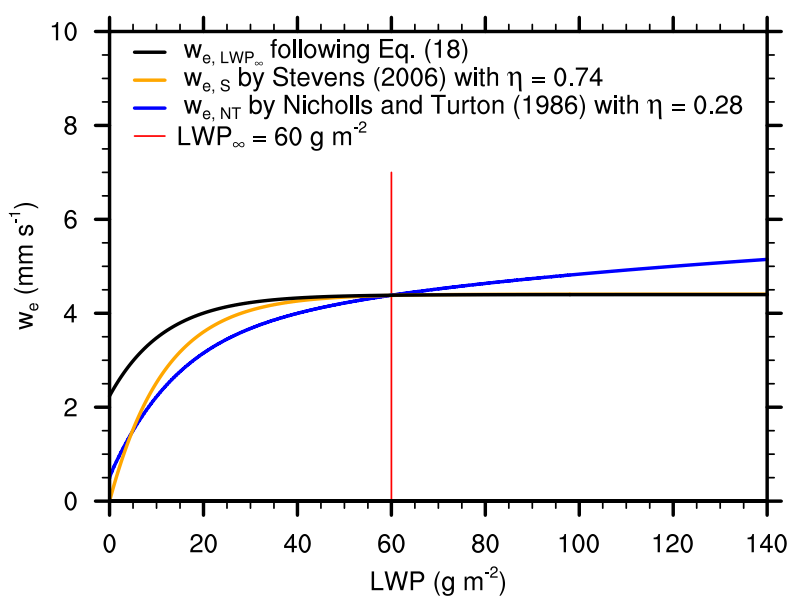

FIG. 4. Entrainment velocity $w_{e}$ as a function of LWP, calculated using Eq. (18) based on steady-state considerations (black line), Stevens (2006) with $\eta=0.74$ (orange line), and Nicholls and Turton (1986) with $\eta=0.28$ (blue line). The red line marks the LWP steady state of $\mathrm{LWP}_{\infty} \approx 60 \mathrm{~g} \mathrm{~m}^{-2}$ seen in our simulations (section 3). Parameters are based on the emulator results presented in section 3: $S_{\theta_{l}}=0.013 \mathrm{~K} \mathrm{~m} \mathrm{~s}^{-1} ; S_{q_{t}}=0.030 \mathrm{~g} \mathrm{~kg}^{-1} \mathrm{~m} \mathrm{~s}^{-1} ; \Delta q_{t}=$ $-8 \mathrm{~g} \mathrm{~kg}^{-1} ; \Delta \theta_{l}=8 \mathrm{~K} ; R_{\theta_{l}}$ determined from Eq. (17) using $F_{0}-F_{1}=$ $48 \mathrm{~W} \mathrm{~m}^{-2}$ and $\kappa=85 \mathrm{~m}^{2} \mathrm{~kg}^{-1} ; \theta_{l}=289 \mathrm{~K} ; q_{t}=8.5 \mathrm{~g} \mathrm{~kg}^{-1}$; and $z_{i}=1000 \mathrm{~m}$.

persist indefinitely in the absence of environmental perturbations.

Overall, $w_{e, \mathrm{LWP}}$ exhibits a similar behavior and the same order of magnitude as $w_{e, S}$ and $w_{e, \mathrm{NT}}$ (Fig. 4). Note, however, that $w_{e, S}$ and $w_{e, \mathrm{LWP}}$ approach a constant value, while $w_{e, \mathrm{NT}}$ increases strictly monotonically with LWP. The latter behavior is expected, and correctly considered in $w_{e, \mathrm{NT}}$, since a larger amount of condensate increases turbulence in the mixed layer due to a generally stronger release of latent heat, as well as increased evaporative cooling at the cloud top following an entrainment event. Since $w_{e, S}$ lacks a realistic LWP dependence, we will limit the following discussion to the comparison of $w_{e, \mathrm{NT}}$ and $w_{e, \mathrm{LWP}}$.

To yield an analytical expression for the LWP steady state, we now combine Eqs. (15), (17), and (18):

$$
\mathrm{LWP}_{\infty}=-\frac{1}{\kappa} \ln \left[1-\frac{\overline{\rho_{a}} c_{p} S_{\theta_{l}}+\zeta \frac{c_{p}}{l_{v}}\left(\overline{\rho_{a}} l S_{v}\right)-\overline{\rho_{a}} c_{p} w_{s}\left(\zeta \Delta q_{t}+\Delta \theta_{l}\right)}{F_{0}-F_{1}}\right]
$$

Note that this expression for $\mathrm{LWP}_{\infty}$ depends primarily on the environmental forcings due to the dynamic surface heat fluxes $\left(\overline{\rho_{a}} c_{p} S_{\theta_{l}}\right.$ and $\left.\overline{\rho_{a}} l_{v} S_{q_{t}}\right)$, temperature and humidity jumps $\left[-\overline{\rho_{a}} c_{p} w_{s}\left(\zeta \Delta q_{t}+\Delta \theta_{l}\right)\right]$, and the potential radiation jump $\left(F_{0}-F_{1}\right)$. However, the dependence on temperature and humidity, as primarily introduced by $\zeta$, should not be underestimated, and is capable of changing $L W P_{\infty}$ by up to $60 \%$ within the range of values relevant for this study. (Since this is not the focus of this study, we do not pursue this further.)

The dependence of $\mathrm{LWP}_{\infty}$ on the environmental forcings is summarized in Fig. 5 (continuous black line; 
(a)

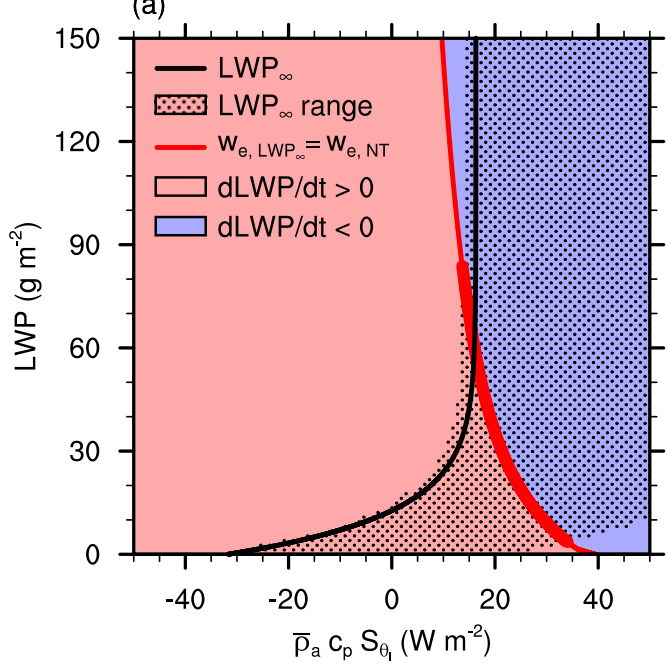

(c)

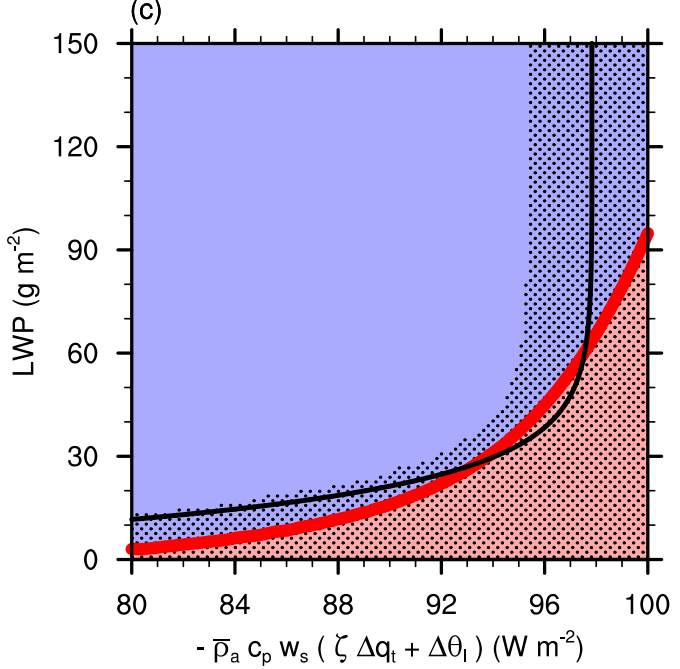

(b)

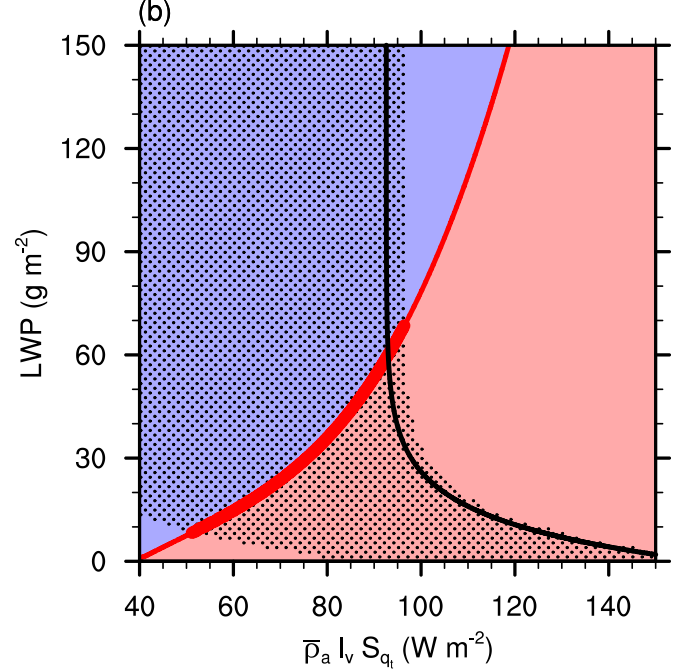

(d)

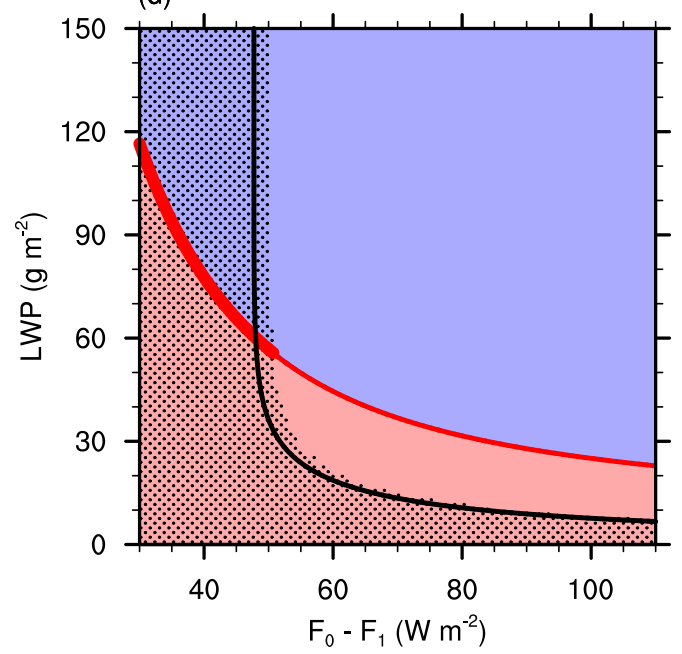

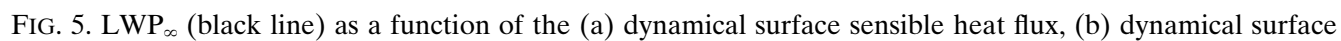
latent heat flux, (c) entrainment, and (d) potential radiation jump. The stippling encloses the range of LWP $\infty$ resulting from varying the subsidence between -4.5 and $-2.0 \mathrm{~mm} \mathrm{~s}^{-1}$. The colored contours show the sign of the LWP tendency resulting from the difference between $w_{e, \mathrm{NT}}$ and $w_{e, \mathrm{LWP}}($ red: $d \mathrm{LWP} / d t>0$; blue: $d \mathrm{LWP} / d t<0$ ). The corresponding zero contour $\left(w_{e, \mathrm{NT}}=w_{e, \mathrm{LWP}_{\infty}}\right)$ is highlighted by a red line, thickened to emphasize overlap with the $\mathrm{LWP}_{\infty}$ range. When not explicitly stated on the abscissa, parameters are based on the emulator results presented in section 3: $\overline{\rho_{a}} c_{p} S_{\theta_{l}}=16 \mathrm{~W} \mathrm{~m}^{-2} ; \overline{\rho_{a}} l_{v} S_{q_{t}}=93 \mathrm{~W} \mathrm{~m}^{-2} ;-\overline{\rho_{a}} c_{p} w_{s}\left(\zeta \Delta q_{t}+\Delta \theta_{l}\right)=97.5 \mathrm{~W} \mathrm{~m}^{-2}$ with $w_{s}=-4.4 \mathrm{~mm} \mathrm{~s}^{-1}$, $\Delta q_{t}=-8 \mathrm{~g} \mathrm{~kg}^{-1}$, and $\Delta \theta_{l}=8 \mathrm{~K} ; F_{0}-F_{1}=48 \mathrm{~W} \mathrm{~m}^{-2} ; \kappa=85 \mathrm{~m}^{2} \mathrm{~kg}^{-1} ; \theta_{l}=289 \mathrm{~K} ; q_{t}=8.5 \mathrm{~g} \mathrm{~kg}^{-1}$; and $z_{i}=1000 \mathrm{~m}$. Furthermore, note that $-\overline{\rho_{a}} c_{p} w_{s}\left(\zeta \Delta q_{t}+\Delta \theta_{l}\right)$ is varied by changing $\Delta \theta_{l}$ only.

the red line, the color shading, and the stippling will be addressed below; parameters for calculating LWP ${ }_{\infty}$ are stated in the caption). Generally, LWP increases $_{\infty}$ to balance the increased warming and drying as a result of larger surface sensible heat flux (Fig. 5a) or stronger temperature and humidity jumps (Fig. 5 c) by radiative cooling. Since the radiative cooling saturates above a certain LWP, a steady state cannot be maintained if the surface sensible heat flux or the jumps exceed a certain threshold, and any cloud existing beyond these thresholds will evaporate eventually. Mathematically speaking, the argument of the logarithm in Eq. (19) approaches 0 or becomes negative, yielding an infinite $\mathrm{LWP}_{\infty}$, or it is not even defined. Similarly, solutions for $\mathrm{LWP}_{\infty}$ do not exist if the surface latent heat flux (Fig. 5b) and potential radiation jump (Fig. 5d) fall below certain values because the compensating radiative cooling saturates for a certain LWP and is therefore unable to counter any further reduction in moistening and cooling. All in all, these thresholds limit the range of surface fluxes, temperature and humidity jumps, and potential radiation jumps for which stratocumuli may exist indefinitely. (Note, however, 
that these thresholds vary with the subsidence $w_{s}$, as addressed below.)

What happens to a cloud when its LWP is perturbed from $L W P_{\infty}$ ? In other words, is $L W P_{\infty}$ a stable or unstable steady state? If the environmental conditions are unchanged, a positive (negative) perturbation in LWP will result in an increase (decrease) in radiative cooling and an increase (decrease) in warming and drying by stronger entrainment, which would exactly balance each other if the entrainment velocity were changed according to $w_{e, \mathrm{LWP}_{\infty}}$ (since it is derived from steady-state considerations). However, the entrainment velocity changes based on the fluid-dynamical conditions. Assuming that this behavior is adequately described by $w_{e, \mathrm{NT}}$, the actual increase (decrease) in the entrainment velocity is stronger than $w_{e, \mathrm{LWP}}$ for a positive (negative) LWP perturbation, resulting in a negative (positive) LWP tendency opposing a perturbation from

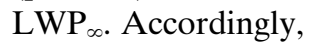

$$
\left.\left.\frac{d w_{e}}{d \mathrm{LWP}}\right|_{\mathrm{LWP}=\mathrm{LWP}_{\infty}} \stackrel{!}{\frac{d w_{e, \mathrm{LWP}}}{d \mathrm{LWP}}}\right|_{\mathrm{LWP}=\mathrm{LWP}_{\infty}}
$$

is a second condition that needs to be fulfilled by $w_{e}$ in addition to the first condition (18) to ensure that LWP is indeed a stable steady state, that is, buffered against perturbations, allowing clouds to return to (or initially attain) their steady-state value.

Combining Eqs. (18) and (20), the difference between $w_{e, \mathrm{NT}}$ and $w_{e, \mathrm{LWP}_{\infty}}$ is depicted in Fig. 5: red and blue contours indicate a positive or negative LWP tendency, respectively, as required from the second condition (20) to oppose an LWP perturbation, while the corresponding zero contour (red line) fulfills the first condition (18), that is, $w_{e, \mathrm{NT}}-w_{e, \mathrm{LWP}}=0$. We easily see that only $\mathrm{LWP}_{\infty}=$ $60 \mathrm{~g} \mathrm{~m}^{-2}$ is a steady state since it crosses the zero contour of $w_{e, \mathrm{NT}}-w_{e, \mathrm{LWP}_{\infty}}$, and it is stable since it exhibits negative LWP tendencies opposing a positive LWP perturbation and positive LWP tendencies opposing a negative LWP perturbation, respectively. The resulting basin of attraction for this stable steady state spans the entire LWP range, that is, attracts developing clouds with negligible LWPs, as well as clouds with a considerable larger LWP, as depicted in our simulations (section 3). Note further that almost all other values of $\mathrm{LWP}_{\infty}$ do not coincide with the zero contour of $w_{e, \mathrm{NT}}-w_{e, \mathrm{LWP}_{\infty}}$ (red line), that is, do not represent a steady state as required by the first condition (18). The only exception is presented in Fig. 5c, where a reduction in the temperature and humidity jumps results in a second stable LWP steady state at $\mathrm{LWP}_{\infty} \approx 30 \mathrm{~g} \mathrm{~m}^{-2}$. We surmise that more LWP steady states can be attained by changes in the subsidence $w_{s}$, relocating $\mathrm{LWP}_{\infty}$ commensurately.
The range of $L W P_{\infty}$ values resulting from changes in $w_{s}$ are enclosed by the stippling in Fig. 5, assuming $w_{s}$ varies between -4.5 and $-2.0 \mathrm{~mm} \mathrm{~s}^{-1}$ for stratocumuli (e.g., Wood 2012). The emerging cross section with the $w_{e, \mathrm{NT}}-w_{e, \mathrm{LWP}}$ zero contour (emphasized by thickened red line) indicates the range of stable $\mathrm{LWP}_{\infty}$ values expected to be observed in nature. If one only considers the variability due to surface fluxes depicted here (Figs. 5a,b), the analytic solution yields a stable LWP $_{\infty}$ range of $10-80 \mathrm{~g} \mathrm{~m}^{-2}$, typical for subtropical stratocumuli (e.g., Zheng et al. 2010). Higher LWP values tend to be found in the midlatitudes (e.g., Wood 2012). And, indeed, LWP $\infty$ yields larger values in colder regions, either by adapting the $\zeta$ parameter accordingly, or reducing the potential radiation jump (Fig. 5d), as expected from a decreased emission of longwave radiation at lower temperatures.

Finally, it is interesting to assess how the analyzed steady-state behavior changes if we assume $w_{e, S}$ by Stevens (2006) instead of $w_{e, \mathrm{NT}}$ by Nicholls and Turton (1986). Starting at $\mathrm{LWP}_{\infty}=60 \mathrm{~g} \mathrm{~m}^{-2}, w_{e, S}$ equals $w_{e, \mathrm{LWP}_{\infty}}$ fulfilling the first condition (18) for all $\mathrm{LWP}_{\infty} \geq 60 \mathrm{~g} \mathrm{~m}^{-2}$ (Fig. 4). However, no restoring force is created since $d w_{e, \mathrm{~S}} /\left.d \mathrm{LWP}\right|_{\mathrm{LWP}=\mathrm{LWP}_{\infty}}=d w_{e, \mathrm{LWP}_{\infty}} /\left.d \mathrm{LWP}\right|_{\mathrm{LWP}=\mathrm{LWP}_{\infty}}=0$, violating the second condition (20) for a stable steady state. This indicates an indifferent steady state for all $L W P_{\infty} \geq 60 \mathrm{~g} \mathrm{~m}^{-2}$. However, this behavior is in contrast to our simulations showing that stratocumuli with $\mathrm{LWP}_{\infty}<60 \mathrm{~g} \mathrm{~m}^{-2}$ are attracted by the steady state at $\mathrm{LWP}_{\infty}=60 \mathrm{~g} \mathrm{~m}^{-2}$. Accordingly, to understand the stable LWP steady state seen in our simulations, it is required that $w_{e}$ increases strictly monotonically with LWP, as is correctly done in the $w_{e, \mathrm{NT}}$ parameterization by Nicholls and Turton (1986) due to the consideration of the effects of increased latent heating and evaporative cooling at higher LWPs.

\section{Discussion and conclusions}

This study has analyzed the development and properties of stratocumulus LWP steady states, using Gaussian process emulation (Glassmeier et al. 2019) and mixed-layer theory (Lilly 1968). Emulation is used to interpolate mixed-layer LWP tendencies diagnosed from 187 LES model runs to understand the process-level contributions of surface fluxes, entrainment, radiation, and surface precipitation in an LWP- $N$ state space. The analysis shows that while the surface fluxes contribute almost constantly over the entire analyzed state space, radiation and entrainment increase strongly with LWP and dominate all other tendencies for LWP $>10 \mathrm{~g} \mathrm{~m}^{-2}$. Albeit significant, the effect of surface precipitation is restricted to a narrow part of the 
state space. The analysis of stratocumulus approaching the LWP steady state shows that it is mainly radiative cooling that forces stratocumuli with a small LWP to the (relatively) larger LWP steady state, while entrainment warming and drying reduce a larger LWP to the (relatively) smaller LWP steady state. Comparisons of our emulators with simple analytical relationships indicate that emulators successfully reproduce process-level properties of stratocumulus, demonstrating that this approach is not only useful for the understanding of systemwide properties (Glassmeier et al.2019), but also the effects of small-scale processes on the entire system.

To further understand the LWP steady state, an analytical solution has been derived from mixed-layer theory to elucidate the influence of surface fluxes, temperature and humidity jumps, and potential radiation jump (maximum possible change of the net radiation flux across the boundary layer) on the LWP steady state, as well as its dynamical stability. The main assumption for our solution is a constant in time cloud-base height, used to define a steady-state entrainment velocity. The actual fluiddynamical entrainment velocity is required to match this entrainment velocity for a steady-state LWP (first condition). To attain a stable LWP steady state, that is, an LWP that is protected against perturbations, it is also required that the LWP derivative of the fluid-dynamical entrainment velocity is larger than the LWP derivative of the aforementioned steady-state entrainment velocity (second condition). Due to this behavior, the fluiddynamical entrainment velocity induces LWP tendencies that oppose perturbations in LWP. It is shown that this is only possible if one includes a processes in the mixed-layer parameterization of the entrainment velocity that increases strictly monotonically with LWP, as is the case for the release of latent heat during condensation and evaporative cooling at the cloud top, in addition to radiative cooling that saturates above a certain LWP.

These insights into the entrainment velocity can be linked to a cloud-radiation-entrainment feedback (Zhu et al. 2005; McMichael et al. 2019): While the LWP determines the entrainment velocity by controlling radiative and evaporative cooling at the cloud top, as well as the general release of latent heat during condensation, the warming and drying by entrainment tend to reduce the LWP. Zhu et al. (2005) argued therefore that minuscule differences in the entrainment velocity lead to significant changes in the LWP, as indicated by the aforementioned first condition for a stable steady state. Our results indicate additionally that the change in the entrainment velocity with LWP (second condition) also needs to be considered to understand if LWP is protected against perturbations. Therefore, our results are of relevance for the setup and interpretation of stratocumulus modeling based on entrainment velocity parameterizations (e.g., Nicholls and Turton 1986; Stevens 2006).

Finally, the dependence of the analytical LWP steady state on changes in environmental parameters has been analyzed. While the LWP steady state increases for a stronger surface sensible heat flux and larger temperature and humidity jumps, it decreases for a stronger surface latent heat flux and a larger potential radiation jump. This (counterintuitive) behavior emanates from the changes in radiative cooling, and hence LWP, required to counteract drying and warming. Since the radiative cooling saturates above a certain LWP, thresholds for the aforementioned environmental parameters are identified, framing the range of environmental conditions that are conducive to stratocumuli. Overall, the analytical solution indicates a range of stable LWP steady states between 10 and $80 \mathrm{~g} \mathrm{~m}^{-2}$, similar to subtropical stratocumuli (e.g., Zheng et al. 2010). Higher LWPs, typical of the midlatitudes (e.g., Wood 2012), can also be obtained from the analytical solution by adapting its parameters accordingly.

While the analytical solution yields a realistic range of LWP steady states, three limitations and their potential impacts need to be addressed: First, neither our simulations nor our analytic solution considers changes in the surface fluxes. Surface fluxes adjust to the temperature and humidity of the mixed layer, with commensurate effects on the LWP steady-state solutions. While this additional variability does not change the general existence of the analytically derived steady states for given surface fluxes (see also Stevens 2006), it certainly will affect the range of stable LWP steady states. Based on Fig. 3, we assume that low LWP steady states $\left(<10 \mathrm{~g} \mathrm{~m}^{-2}\right)$ might be most susceptible to variable surface fluxes. For higher LWPs, the contribution of surface fluxes can be assumed negligible, since the LWP budget is dominated by the equilibrium between the warming and drying by entrainment and the cooling due to the emission of longwave radiation. Second, the analytical solution does not include effects of precipitation. While this is generally acceptable in the nonprecipitating state space and most of the precipitating state space without surface precipitation (cf. Figs. 2, 3), it contributes as another source for warming and drying that would require a higher LWP steady state to provide the necessary radiative cooling. If, however, surface precipitation becomes too strong, a steady-state solution might not be possible. On the other hand, warming and drying due to surface 
precipitation increase strictly monotonically with LWP. Hence, it has the same analytical properties required for the entrainment velocity to attain a stable LWP steady state. Therefore, surface precipitation might also stabilize LWP steady states as also indicated in other studies (e.g., Stevens et al. 1998). Third, the analytical solution assumes nocturnal conditions, that is, shortwave radiative heating of the cloud layer during daytime is neglected (e.g., Wood et al. 2002). This additional heating requires larger steady-state LWPs to increase the counteracting radiative cooling commensurately, potentially modulated by the stronger dependence of shortwave absorption on droplet radius and hence $N$ (e.g., Stephens 1978). If, however, shortwave heating becomes too large, a steady-state solution might even become impossible as is the case for the sensible heat flux or entrainment drying and heating discussed above (cf. section 4), reflecting the thinning typically observed for daytime stratocumuli.

While these limitations might alter the range of potential LWP steady states under the discussed circumstances, they do not question the general dynamics leading to stable LWP steady states. Therefore, stable LWP steady states are likely be an integral component of stratocumulus cloud systems, and a solid understanding of their behavior could help constrain responses of this important cloud type to climate change.

Acknowledgments. This research was performed while Fabian Hoffmann held a Visiting Fellowship of the Cooperative Institute for Research in Environmental Sciences (CIRES) at the University of Colorado Boulder and the NOAA Earth System Research Laboratory. Franziska Glassmeier acknowledges support by a National Research Council Research Associateship award at NOAA, by the Branco Weiss FellowshipSociety in Science, administered by the ETH Zürich, and by a Veni grant of the Dutch Research Council (NWO). Franziska Glassmeier thanks Stephan de Roode for helpful discussions. Marat Khairoutdinov graciously provided the SAM model. Finally, the authors thank Rob Wood and two anonymous reviewers for their comments on the manuscript.

\section{REFERENCES}

Ackerman, A. S., M. P. Kirkpatrick, D. E. Stevens, and O. B. Toon, 2004: The impact of humidity above stratiform clouds on indirect aerosol climate forcing. Nature, 432, 1014-1017, https:// doi.org/10.1038/nature03174.

— , and Coauthors, 2009: Large-eddy simulations of a drizzling, stratocumulus-topped marine boundary layer. Mon. Wea. Rev., 137, 1083-1110, https://doi.org/10.1175/2008MWR2582.1.

Albrecht, B. A., C. S. Bretherton, D. Johnson, W. H. Scubert, and A. S. Frisch, 1995: The Atlantic Stratocumulus Transition
Experiment-ASTEX. Bull. Amer. Meteor. Soc., 76, 889904, https://doi.org/10.1175/1520-0477(1995)076<0889:TASTE> 2.0.CO;2.

Baker, M. B., and R. J. Charlson, 1990: Bistability of CCN concentrations and thermodynamics in the cloud-topped boundary layer. Nature, 345, 142-145, https://doi.org/10.1038/ $345142 \mathrm{a} 0$.

Boucher, O., and Coauthors, 2013: Clouds and aerosols. Climate Change 2013: The Physical Science Basis, T. F. Stocker et al., Eds., Cambridge University Press, 571-657.

Bretherton, C. S., P. N. Blossey, and J. Uchida, 2007: Cloud droplet sedimentation, entrainment efficiency, and subtropical stratocumulus albedo. Geophys. Res. Lett., 34, L03813, https:// doi.org/10.1029/2006GL027648.

_ J. Uchida, and P. N. Blossey, 2010: Slow manifolds and multiple equilibria in stratocumulus-capped boundary layers. J. Adv. Model. Earth Syst., 2, 14, https://doi.org/10.3894/ JAMES.2010.2.14.

Caldwell, P., and C. S. Bretherton, 2009: Response of a subtropical stratocumulus-capped mixed layer to climate and aerosol changes. J. Climate, 22, 20-38, https://doi.org/10.1175/ 2008JCLI1967.1.

Clough, S., M. Shephard, E. Mlawer, J. Delamere, M. Iacono, K. Cady-Pereira, S. Boukabara, and P. Brown, 2005: Atmospheric radiative transfer modeling: A summary of the AER codes. J. Quant. Spectrosc. Radiat. Transfer, 91, 233-244, https:// doi.org/10.1016/j.jqsrt.2004.05.058.

Dal Gesso, S., A. Siebesma, S. de Roode, and J. van Wessem, 2014: A mixed-layer model perspective on stratocumulus steady states in a perturbed climate. Quart. J. Roy. Meteor. Soc., 140, 2119-2131, https://doi.org/10.1002/qj.2282.

Duynkerke, P. G., and Coauthors, 1999: Intercomparison of threeand one-dimensional model simulations and aircraft observations of stratocumulus. Bound.-Layer Meteor., 92, 453-487, https://doi.org/10.1023/A:1002006919256.

Feingold, G., R. Walko, B. Stevens, and W. Cotton, 1998: Simulations of marine stratocumulus using a new microphysical parameterization scheme. Atmos. Res., 47-48, 505-528, https://doi.org/10.1016/S0169-8095(98)00058-1.

Garrett, T. J., L. F. Radke, and P. V. Hobbs, 2002: Aerosol effects on cloud emissivity and surface longwave heating in the arctic. J. Atmos. Sci., 59, 769-778, https://doi.org/10.1175/15200469(2002)059<0769:AEOCEA > 2.0.CO;2.

Gerber, H., 1996: Microphysics of marine stratocumulus clouds with two drizzle modes. J. Atmos. Sci., 53, 1649-1662, https://doi.org/ 10.1175/1520-0469(1996)053<1649:MOMSCW>2.0.CO;2.

Ghonima, M. S., J. R. Norris, T. Heus, and J. Kleissl, 2015: Reconciling and validating the cloud thickness and liquid water path tendencies proposed by R. Wood and J. J. van der Dussen et al. J. Atmos. Sci., 72, 2033-2040, https://doi.org/ 10.1175/JAS-D-14-0287.1.

Glassmeier, F., F. Hoffmann, J. S. Johnson, T. Yamaguchi, K. S. Carslaw, and G. Feingold, 2019: An emulator approach to stratocumulus susceptibility. Atmos. Chem. Phys., 19, $10191-$ 10 203, https://doi.org/10.5194/acp-19-10191-2019.

Goren, T., and D. Rosenfeld, 2015: Extensive closed cell marine stratocumulus downwind of Europe-A large aerosol cloud mediated radiative effect or forcing? J. Geophys. Res. Atmos., 120, 6098-6116, https://doi.org/10.1002/2015JD023176.

Hoffmann, F., 2016: The effect of spurious cloud edge supersaturations in Lagrangian cloud models: An analytical and numerical study. Mon. Wea. Rev., 144, 107-118, https://doi.org/10.1175/ MWR-D-15-0234.1. 
_- , and G. Feingold, 2019: Entrainment and mixing in stratocumulus: Effects of a new explicit subgrid-scale scheme for large-eddy simulations with particle-based microphysics. J. Atmos. Sci., 76, 1955-1973, https://doi.org/10.1175/JAS-D18-0318.1.

Kazil, J., T. Yamaguchi, and G. Feingold, 2017: Mesoscale organization, entrainment, and the properties of a closed-cell stratocumulus cloud. J. Adv. Model. Earth Syst., 9, 22142229, https://doi.org/10.1002/2017MS001072.

Khairoutdinov, M. F., and D. A. Randall, 2003: Cloud resolving modeling of the ARM summer 1997 IOP: Model formulation, results, uncertainties, and sensitivities. J. Atmos. Sci., 60, 607-625, https://doi.org/10.1175/1520-0469(2003) $060<0607$ :CRMOTA $>2.0 . \mathrm{CO} ; 2$.

Kostinski, A., 2008: Drizzle rates versus cloud depths for marine stratocumuli. Environ. Res. Lett., 3, 045019, https://doi.org/ 10.1088/1748-9326/3/4/045019.

Lehmann, K., H. Siebert, and R. A. Shaw, 2009: Homogeneous and inhomogeneous mixing in cumulus clouds: Dependence on local turbulence structure. J. Atmos. Sci., 66, 3641-3659, https://doi.org/10.1175/2009JAS3012.1.

Lilly, D. K., 1968: Models of cloud-topped mixed layers under a strong inversion. Quart. J. Roy. Meteor. Soc., 94, 292-309, https://doi.org/10.1002/qj.49709440106.

McComiskey, A., G. Feingold, A. S. Frisch, D. D. Turner, M. A Miller, J. C. Chiu, Q. Min, and J. A. Ogren, 2009: An assessment of aerosol-cloud interactions in marine stratus clouds based on surface remote sensing. J. Geophys. Res., 114, D09203, https://doi.org/10.1029/2008JD011006.

McMichael, L. A., D. B. Mechem, S. Wang, Q. Wang, Y. L. Kogan, and J. Teixeira, 2019: Assessing the mechanisms governing the daytime evolution of marine stratocumulus using large-eddy simulation. Quart. J. Roy. Meteor. Soc., 145, 845-866, https:// doi.org/10.1002/qj.3469.

Mellado, J. P., 2017: Cloud-top entrainment in stratocumulus clouds. Annu. Rev. Fluid Mech., 49, 145-169, https://doi.org/ 10.1146/annurev-fluid-010816-060231.

Nicholls, S., 1984: The dynamics of stratocumulus: Aircraft observations and comparisons with a mixed layer model. Quart. J. Roy. Meteor. Soc., 110, 783-820, https://doi.org/10.1002/qj.49711046603.

_ - and J. Turton, 1986: An observational study of the structure of stratiform cloud sheets: Part II. Entrainment. Quart. J. Roy. Meteor. Soc., 112, 461-480, https://doi.org/10.1002/qj.49711247210.

O'Hagan, A., 2006: Bayesian analysis of computer code outputs: A tutorial. Reliab. Eng. Syst. Saf., 91, 1290-1300, https://doi.org/ 10.1016/j.ress.2005.11.025.

Randall, D. A., 1984: Stratocumulus cloud deepening through entrainment. Tellus, 36A, 446-457, https://doi.org/10.3402/ tellusa.v36i5.11646.

Rasmussen, C., and C. K. I. Williams, 2006: Gaussian Processes for Machine Learning. MIT Press, 248 pp.

Savic-Jovcic, V., and B. Stevens, 2008: The structure and mesoscale organization of precipitating stratocumulus. J. Atmos. Sci., 65 , 1587-1605, https://doi.org/10.1175/2007JAS2456.1.

Sharon, T. M., B. A. Albrecht, H. H. Jonsson, P. Minnis, M. M. Khaiyer, T. M. van Reken, J. Seinfeld, and R. Flagan, 2006: Aerosol and cloud microphysical characteristics of rifts and gradients in maritime stratocumulus clouds. J. Atmos. Sci., 63, 983-997, https://doi.org/10.1175/JAS3667.1.
Stephens, G., 1978: Radiation profiles in extended water clouds. I: Theory. J. Atmos. Sci., 35, 2111-2122, https://doi.org/10.1175/ 1520-0469(1978)035<2111:RPIEWC >2.0.CO;2.

Stevens, B., 2006: Bulk boundary-layer concepts for simplified models of tropical dynamics. Theor. Comput. Fluid Dyn., 20, 279-304, https://doi.org/10.1007/s00162-006-0032-z.

—, R. L. Walko, W. R. Cotton, and G. Feingold, 1996: The spurious production of cloud-edge supersaturations by Eulerian models. Mon. Wea. Rev., 124, 1034-1041, https://doi.org/10.1175/ 1520-0493(1996)124<1034:TSPOCE > 2.0.CO;2.

— , W. R. Cotton, G. Feingold, and C.-H. Moeng, 1998: Large-eddy simulations of strongly precipitating, shallow, stratocumulustopped boundary layers. J. Atmos. Sci., 55, 3616-3638, https:// doi.org/10.1175/1520-0469(1998)055<3616:LESOSP >2.0.CO;2. , and Coauthors, 2003: Dynamics and Chemistry of Marine Stratocumulus-DYCOMS-II. Bull. Amer. Meteor. Soc., 84, 579-594, https://doi.org/10.1175/BAMS-84-5-579.

— , and Coauthors, 2005: Evaluation of large-eddy simulations via observations of nocturnal marine stratocumulus. Mon. Wea. Rev., 133, 1443-1462, https://doi.org/10.1175/MWR2930.1.

Turner, J., 1973: Buoyancy Effects in Fluids. Cambridge University Press, $367 \mathrm{pp}$.

Uchida, J., C. Bretherton, and P. Blossey, 2010: The sensitivity of stratocumulus-capped mixed layers to cloud droplet concentration: Do LES and mixed-layer models agree? Atmos. Chem. Phys., 10, 4097-4109, https://doi.org/10.5194/acp-104097-2010.

van der Dussen, J. J., S. R. de Roode, and A. P. Siebesma, 2014: Factors controlling rapid stratocumulus cloud thinning. J. Atmos. Sci., 71, 655-664, https://doi.org/10.1175/JAS-D-130114.1.

Wang, H., and G. Feingold, 2009: Modeling mesoscale cellular structures and drizzle in marine stratocumulus. Part II: The microphysics and dynamics of the boundary region between open and closed cells. J. Atmos. Sci., 66, 3257-3275, https:// doi.org/10.1175/2009JAS3120.1.

Wang, S., Q. Wang, and G. Feingold, 2003: Turbulence, condensation, and liquid water transport in numerically simulated nonprecipitating stratocumulus clouds. J. Atmos. Sci., 60, 262-278, https://doi.org/10.1175/1520-0469(2003) $060<0262$ :TCALWT $>2.0$. CO;2.

Wood, R., 2007: Cancellation of aerosol indirect effects in marine stratocumulus through cloud thinning. J. Atmos. Sci., 64, $2657-$ 2669, https://doi.org/10.1175/JAS3942.1.

_ 2012: Stratocumulus clouds. Mon. Wea. Rev., 140, 2373-2423, https://doi.org/10.1175/MWR-D-11-00121.1.

, C. Bretherton, and D. Hartmann, 2002: Diurnal cycle of liquid water path over the subtropical and tropical oceans. Geophys. Res. Lett., 29, 2092, https://doi.org/10.1029/ 2002 GL015371.

Zheng, X., B. Albrecht, P. Minnis, K. Ayers, and H. H. Jonson, 2010: Observed aerosol and liquid water path relationships in marine stratocumulus. Geophys. Res. Lett., 37, L17803, https:// doi.org/10.1029/2010GL044095.

Zhu, P., and Coauthors, 2005: Intercomparison and interpretation of single-column model simulations of a nocturnal stratocumulustopped marine boundary layer. Mon. Wea. Rev., 133, 2741-2758, https://doi.org/10.1175/MWR2997.1. 